\title{
MicroRNA expression patterns and signalling pathways in the development and progression of childhood solid tumours
}

\author{
Anna L. Leichter ${ }^{1}$, Michael J. Sullivan ${ }^{3}$, Michael R. Eccles ${ }^{1,2^{*}}$ and Aniruddha Chatterjee ${ }^{1,2^{*}}$ (D)
}

\begin{abstract}
The development of childhood solid tumours is tied to early developmental processes. These tumours may be complex and heterogeneous, and elucidating the aberrant mechanisms that alter the early embryonic environment and lead to disease is essential to our understanding of how these tumours function. MicroRNAs (miRNAs) are vital regulators of gene expression at all stages of development, and their crosstalk via developmental signalling pathways is essential for orchestrating regulatory control in processes such as proliferation, differentiation and apoptosis of cells. Oncogenesis, from aberrant miRNA expression, can occur through amplification and overexpression of oncogenic miRNAs (oncomiRs), genetic loss of tumour suppressor miRNAs, and global miRNA reduction from genetic and epigenetic alterations in the components regulating miRNA biogenesis. While few driver mutations have been identified in many of these types of tumours, abnormal miRNA expression has been found in a number of childhood solid tumours compared to normal tissue. An exploration of the network of key developmental pathways and interacting miRNAs may provide insight into the development of childhood solid malignancies and how key regulators are affected. Here we present a comprehensive introduction to the roles and implications of miRNAs in normal early development and childhood solid tumours, highlighting several tumours in depth, including embryonal brain tumours, neuroblastoma, osteosarcoma, Wilms tumour, and hepatoblastoma. In light of recent literature describing newer classifications and subtyping of tumours based on miRNA profiling, we discuss commonly identified miRNAs, clusters or families associated with several solid tumours and future directions for improving therapeutic approaches.
\end{abstract}

Keywords: MicroRNAs, Early development, Childhood solid tumours, Neuroblastoma, Medulloblastoma, Osteosarcoma, Wilms Tumour, Hepatoblastoma

\section{Background}

MicroRNAs (miRNAs) are a group of small non-coding RNAs, around 19-22 nucleotides in length, first discovered in nematodes (Caenorhabditis elgans) in 1993 [1]. Now there are thousands of miRNAs identified in many different eukaryote species [2]. Previously, miRNAs and other noncoding RNAs were dismissed as transcriptional noise $[3,4]$. However, recently the ENCODE project

\footnotetext{
* Correspondence: michael.eccles@otago.ac.nz;

aniruddha.chatterjee@otago.ac.nz

'Department of Pathology, Dunedin School of Medicine, University of Otago,

56 Hanover Street, P.O. Box 913, Dunedin 9016, New Zealand

Full list of author information is available at the end of the article
}

revealed that in the human genome there is a vast network of important interactions that occur between regulatory elements, primarily composed of transcription factors and miRNAs [5-7]. miRNAs can regulate gene expression in several ways, through DNA interaction, translational repression or by directly targeting mRNA degradation, and they play vital roles in nearly all biological pathways [8]. With this characterization we now know different sets of miRNAs are expressed in specific cell and tissue types and therefore they play an important role in shaping cellular identity $[9,10]$. In addition, miRNAs have been shown to regulate oncogenes, tumour suppressor genes and have an impact on cell cycle control, apoptosis, cell migration and 
angiogenesis [11-19]. Taken together, these discoveries provide insight into the importance of the roles of miRNAs in maintaining normal cellular function and how disruptions in miRNA expression profiles may heavily impact the development, differentiation, and control of growth leading to diseases such as cancer.

Cancer is a disease of diverse genetic and epigenetic complexity involving changes in gene expression [20-22]. For a long time, carcinogenesis was largely attributed to abnormalities in oncogenes and tumour suppressing genes. It is now widely recognized that miRNAs also play critical roles in cancer. Aberrant miRNA expression associated with cancer development can occur through a number of different types of mechanisms, each of which is a critical event that could greatly alter early development and give rise to the pathogenesis of childhood cancers.

There has been recent work indicating that global miRNA profiles are able to classify human cancers tissues, including paediatric solid tumours [23, 24]. An investigation into biomarkers and risk stratification in childhood solid tumours highlighted that specific serum miRNA profiles can be identified in childhood solid tumours. The results supported the proposed use of miRNA profiling from serum as a non-invasive method with the potential to diagnose childhood solid tumours [25]. Also of note is the emerging evidence of disrupted components of the miRNA biogenesis pathway, which, if altered, affect miRNA expression levels on a global scale. Enzymes involved in the production of mature miRNAs have been implicated in certain childhood cancers, including neuroblastomas and Wilms tumour [26-28].

In recent years, the concepts of cell of origin (COO) and cancer stem cells (CSCs) have gained traction; these concepts are distinct. The $\mathrm{COO}$ is a normal cell, which has acquired the first cancer promoting mutation, and CSCs are the cellular component of a tumour that maintains malignant growth. Therefore, COOs and CSCs are cancer initiating and cancer propagating respectively. Investigators have identified a number of miRNAs associated with CSCs, differentially expressed in six paediatric solid tumour cell lines [29]. The identified potential targets were further investigated using in silico biological analytical processes, which revealed four annotated pathways that were enriched: cell cycle, cell proliferation, p53 and TGF-beta/BMP. This highlights an important consideration; the actions of miRNAs on key critical developmental pathways could have major effects on how these pathways function, and could be deleteriously affected by deregulated miRNAs, causing a chain of events which may lead to an environment where cancer develops [30].

The scope of this review aims to address the current state of miRNA research in relation to childhood solid tumours. Due to the necessarily precise genetic regulation that occurs during development, it is plausible that
miRNAs play a major role in childhood cancers. A deeper understanding of the links between the deregulation of miRNAs and childhood cancers can improve the way children are diagnosed and treated. Here we briefly describe miRNA biogenesis, how miRNAs function in early development and their ability to act as tumour suppressors and oncomiRs. In addition, the key developmental pathways and how they lead to malignancies in different organs is examined through the lens of miRNA action. We explore several childhood solid tumours in detail, neuroblastoma, osteosarcoma, nephroblastoma (Wilms tumour), hepatoblastoma, and several types of brain tumours. In the following discussion of these solid tumour types, miRNAs (or families) identified as aberrantly expressed in multiple tumour types are highlighted in an effort to understand where connections between the developmental processes and childhood solid tumours might be used as a basis for discovering shared mechanisms. It remains challenging to interpret how the many targets of individual miRNAs directly affect downstream processes, leading to development or progression of childhood cancer; however, pending accurate interpretations, this may lead to the discovery of targetable pathways and assist in the generation of new therapies.

\section{The miRNA biogenesis process}

miRNAs are initially processed from precursor molecules (pri-miRNAs) in the nucleus [31, 32]. Pri-miRNAs are transcribed by RNA polymerase II/III from independent genes, or intronic sequences. The pri-miRNAs fold into hairpins, and are cleaved by the enzymes Drosha and Dicer in a two-step processing function [33, 34]. First the nuclear localised complex of DROSHA and DGCR8 cleaves the pri-miRNA, producing a $\sim 70$ nucleotide pre-miRNA. This is exported to the cytoplasm by the complex Exportin 5-Ran-GTP, where TRBP and DICER process the pre-miRNA to yield a $\sim 20 \mathrm{bp}$ miRNA/miRNA* coupled pair $[35,36]$. One strand represents the 5' miRNA, whereas the other strand represents the 3' miRNA. Depending on the specific miRNA one of the strands is preferentially degraded over the other more highly expressed miRNA [37]. The preferentially expressed miRNA is incorporated into the miRNA induced silencing complex (miRISC) which allows miRNAs to target mRNAs and induce translational repression or deadenylation, and subsequent degradation, leading to rapid silencing of the targeted mRNA transcript gene product [38-41].

\section{miRNA mediated regulation of the genome and key developmental pathways}

Through evolution, miRNAs and their mechanistic features for targeting mRNA have been strongly conserved. An important class of gene regulatory molecules, they 
are often considered "master regulators" of gene expression, because a single miRNA can bind to, and consequently impact the expression of a number of different transcripts. Previous evidence has suggested that the average miRNA has approximately 100 target sites [42]. At the current time miRTarBase, (an experimentally validated miRNA target interaction database), states there are 2,619 known human miRNAs validated to target 12,738 genes [43].

The reason miRNAs can affect multiple targets is due to the mechanism of action in which the miRNAs base-pair to their targets, involving flexible complementary pairing with the mRNA. miRNAs base-pair to their target mRNA on the 3'-UTR, where there are miRNA recognition elements (MREs). miRNAs implement the use of a critical region referred to as the "seed region", a region on the 5 ' end of the miRNA containing 2-8 nucleotides [44, 45]. Interestingly, asymmetry is commonly observed for matches between the miRNA and its target. The 5' end of miRNA tends to have a greater number of complementary bases than the 3' end. A key finding indicates that as few as seven base pairs of complementarity to the miRNA $5^{\prime}$ end are sufficient to provide regulation [46]. Additionally, 3' end complementarity may serve as a specificity factor, allowing the possibility of different sites to become differentially regulated by different miRNA family members. These attributes are necessary in development, where dynamic protein expression occurs in order to orchestrate a number of critical actions, such as cell lineage decisions and the resulting morphogenetic events. If additionally we consider that there are a surprisingly large number of miRNA target sites within the genome, it becomes apparent that miRNAs are capable of a widespread impact on gene regulation [42].

In the earliest embryonic stages, a single cell zygote transforms to a morula and then to a blastocyst. During this period the zygote initiates the first cell division and the first lineage cell undergoes differentiation into the inner cell mass and the trophectoderm. The processes involved in these events are complex and regulated by multiple signalling pathways with related biological functions such as cell division and growth, differentiation, migration, apoptosis, transformation and polarity. Not surprisingly these functions are tightly interconnected and disruptions in these networks may lead to abnormal development, disease or even fatality. Several signalling transduction pathways have been demonstrated to be involved in the early process of mammalian embryonic development, including; mitogenactivated protein kinase (MAPK); phosphatidylinositol 3kinase (PI3K)/Akt; Wingless (Wnt)/ $\beta$-catenin; Notch; bone morphogenetic protein (BMP)/transforming growth factor (TGF- $\beta$ ); Hedgehog and Janus-activated kinase (JAK)/signal transducer and activator of transcription (STAT). While these pathways contribute to central events in development, their stage-specific expression is key to orchestrating the correct processes with the correct timing; this is where miRNAs may have an important role. The miRNA expression in preimplantation development is a difficult area to research, particularly in humans and therefore much of this information is still relatively unexplored. However miRNA targeting of developmental pathways does occur early in development and the identified action of specific miRNAs targeting critical signalling pathways provides evidence of the importance of these molecules in regulating early development and assisting in more specified development in separate lineages, and body systems later on (Fig. 1) [47].

There are a large number of miRNAs that have been confirmed to regulate components in essential developmental pathways. Crosstalk between these signalling pathways and miRNAs emphasises that miRNAs contribute largely during embryogenesis and early development. An example is the Wnt signalling pathway, which is a major contributor in controlling biological processes and is extensively researched. There is supportive evidence of miRNAs regulating WNT signalling components and being associated with various cancers in the literature. The signalling pathways critical in early development are interwoven with the function of numerous miRNAs and the affect of aberrant miRNA expression could have widespread consequences in the development of a specific organ or body system. Additionally, mice lacking the essential miRNA-processing enzyme, Dicer, are embryonically lethal before embryonic day (E) 7.5, suggesting the roles of the components of the machinery which produce functional miRNAs, and the miRNAs themselves, are essential in embryogenesis [48].

\section{miRNA function and links to childhood cancer development and progression}

There are a number of mechanisms that may affect the miRNA profile in a specific tissue or group of cells. These events can alter expression in both oncomiRs and tumour suppressor miRNAs, or on a more global scale, mutations in components of the miRNA biogenesis pathway may affect larger groups of miRNAs, and their ability to mediate repression of target mRNA (Fig. 2.) The let-7 family were identified early as a group of influential miRNAs. They are well researched and have been shown to regulate expression of the RAS oncogenes. Mutations in RAS oncogenes are present in around $25-30 \%$ of all human tumours. In vitro experiments on a pulmonary adenoma cell lineage indicate that let-7 is able to inhibit cell proliferation through $R A S$, which suggests it may play a role as a tumour suppressor [49]. From this investigation, it was determined that let-7 miRNAs regulate the expression of the RAS protein and are also able to subsequently affect cell proliferation rates through the downstream MAPK signalling cascade. 


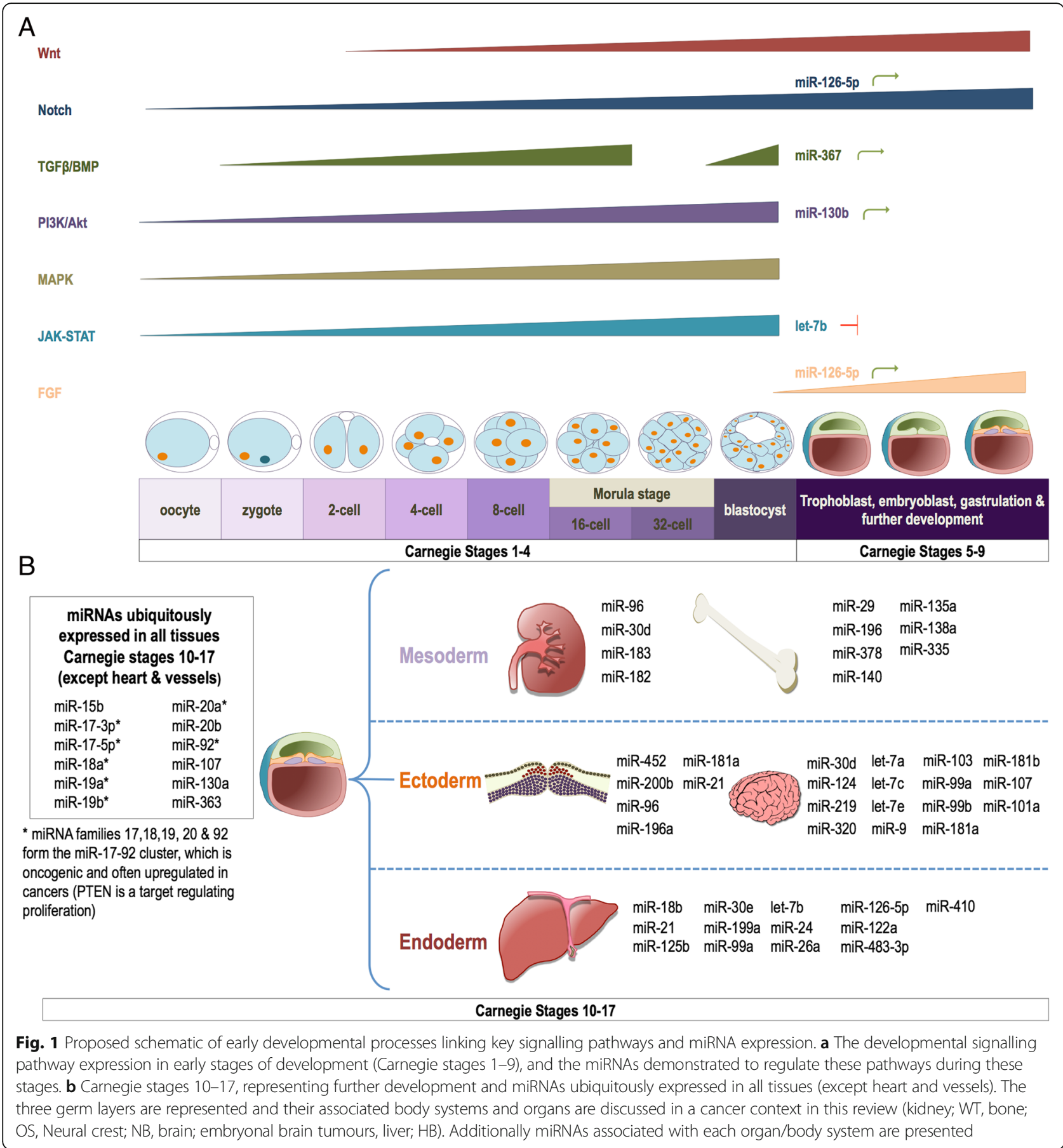

Although the links between miRNAs and the initiation and progression of cancer are supported, the area which remains difficult to interpret and requires further exploration is the exact mechanism by which miRNAs function to cause downstream effects, or conversely, how miRNA genes are influenced by other events which may alter the normal miRNA profile. Often miRNA expression is repressed in cancer compared to normal tissues; contrarily, there are also some miRNAs overexpressed in cancer [24].
In addition to the deletion and mutation of miRNA genes, aberrant methylation may cause epigenetic inactivation with subsequent transcriptional suppression. Aberrant hypermethylation in mir-9-1, mir-124a, mir-148, mir152 and mir-663 was observed in up to $86 \%$ of cases in a cohort of 71 primary breast cancer tissues [50]. Additionally, global or local aberrant methylation of miRNA genes may also alter the miRNA profile of an individual, subsequently providing a vulnerable situation in which normal 


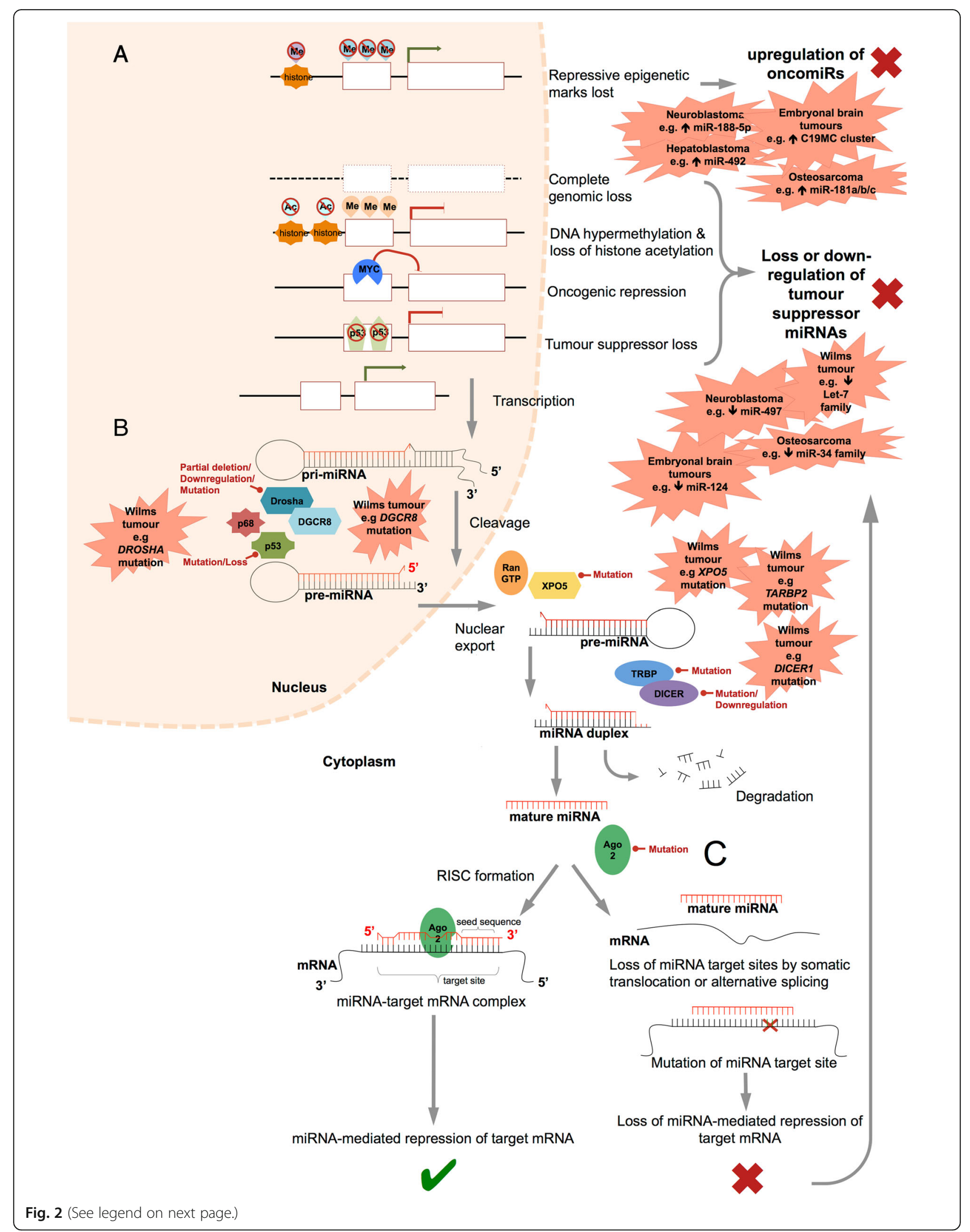


(See figure on previous page.)

Fig. 2 The mechanisms by which alteration of normal miRNA profiles can occur, leading to aberrant miRNA profiles in childhood solid tumours. Examples of aberrant expression and disrupted miRNA biogenesis are illustrated and are supported by validation in the literature. a Disruptions to miRNA genes, resulting in upregulation of oncogenic miRNAs or downregulation, or complete loss of expression (tumour suppressor miRNAs). $\mathbf{b}$ Components of the miRNA biogenesis pathway that can be altered, affecting production of mature functioning miRNAs. $\mathbf{c}$ Events which alter the target mRNA and affect the ability of the mature miRNA to bind

genetic regulation is lost and the development of cancer could arise. In relation to this, epigenetic changes of miRNA promoters, such as alteration of their methylation status or their histone patterning can also induce changes in miRNA expression [51]. A number of studies have investigated the role of methylation and how it may fit in with disease progression and development. What is important to note here, and can be applied to other types of cancer, are the mechanisms by which epigenetic regulation can occur. Some examples of this include the downregulation of Let-7 family, which has been shown to be downregulated through DNA and histone methylation in gastric cancer, or miR-34b and miR-34c. Or miRNAs can be downregulated through hypermethylation of the neighbouring CpG islands. These miRNAs are also implicated in childhood cancers suggesting a common role in oncogenesis [52] (Table 1). Accumulating evidence suggests that aberrant methylation of certain miRNA genes may disrupt a number of key signalling pathways. This could have major effects in the developmental process, which relies heavily on the maintenance of regulated signalling to ensure controlled growth, and without which tumourigenesis may arise (Fig. 2).

Cancer-related transcriptional control of miRNAs has also been demonstrated by the observation of transcriptional activation of the miR-17/92 cluster induced by the $M Y C$ oncogene, the upregulation of which modulates the anti-apoptotic and proliferative actions of E2F1, mediating the $M Y C$ proliferative effect [13]. Altered miRNA expression clearly contributes to many cancers through a variety of different mechanisms, and will continue to provide insight into cancer onset and progression.

\section{A brief account of childhood solid tumours}

In childhood cancers, the pathogenesis of tumours is often tightly linked with the processes of development such as organogenesis, tissue growth and maturation [53-58]. This area of research is growing; new resources collating and examining the links between developmental biology and oncology are emerging to assist in bringing together the two research communities to help apply discoveries in the search for targeted therapies [59]. The processes regulating fetal and postnatal growth and development are controlled and coordinated by multiple developmental pathways, such as Hox, WNT, Notch and Hedgehog [47]. Disruption of these strictly regulated pathways through germline or somatic mutation, or epigenetic or transcriptional dysregulation can transform specific tissues, giving rise to the early onset of cancer during childhood [30].

The most common types of childhood cancers are leukaemia, brain and central nervous systems tumours and lymphomas. In addition to these cancers, are the embryonal solid tumours of the kidney (Wilms tumour), neural crest (neuroblastoma), muscle (rhabdomyosarcoma), eye (retinoblastoma), and the liver (hepatoblastoma). Embryonal solid tumours of childhood are more commonly sporadic than heritable. In some cases they are associated with various syndromes such as BeckwithWiedemann syndrome (BWS) and in patients with familial adenomatous polyposis (FAP) [60]. The particular histological features of the malignant tumours, and the appearance of corrupted tissue development, are what characterise this heterogeneous group of tumours.

\section{The role of miRNAs in childhood cancer}

It is essential to continue research to build a better understanding of the role miRNAs in the development of childhood cancers. It is clear that many of these cancers are tightly associated with irregular events occurring during development, and what we can learn from the inclusion and exploration of these vital regulatory elements may be the key to a deeper understanding of the complex nature of how childhood cancers arise. Another complex issue involving childhood cancers, where miRNAs may provide valuable insight, is the development of treatment resistance. It is important to identify aberrant miRNA expression associated with pathogenesis and also drug resistance, especially chemoresistance, as this may be critical in providing lasting and effective treatments for children [61].

The following sections review several types of childhood solid tumours, describing common features and key developmental pathways that have been identified to contribute to embryogenesis and disease. The following childhood cancers were selected based on their association with a variety of affected organs or body systems, (e.g. kidneys, liver and brain as well as the sympathetic nervous system and skeletal system), and because recent literature has uncovered unique links to miRNAs and the development of these solid tumours. In addition, the childhood cancers discussed are those where the etiology remains unclear and the involvement of miRNAs could help to explain some of the unique qualities of the 
Table 1 Summary of miRNAs that are consistently downregulated in different childhood solid tumours

\begin{tabular}{|c|c|c|c|}
\hline miRNA/miRNA cluster & $\begin{array}{l}\text { Childhood cancer } \\
\text { type* }\end{array}$ & Comments & Ref \\
\hline miR-16 & OS & Differentially expressed compared to healthy bone tissue & [103] \\
\hline miR-29b & OS & Differentially expressed compared to healthy bone tissue & [103] \\
\hline miR-142-5p & OS & Differentially expressed compared to healthy bone tissue & [103] \\
\hline $\begin{array}{ll}\text { miR- } & \text { miR-34a, } \\
34 & \text { miR-34b, miR-34c } \\
\text { family } & \end{array}$ & $\mathrm{NB}, \mathrm{OS}$ & $\begin{array}{l}\text { Targets MYCN, identified as tumour suppressors, often } \\
\text { found in } 1 p \text { deletion in MNA NB tumours, targeted by p53 }\end{array}$ & $\begin{array}{l}\text { [79], [82], } \\
\text { [84], [97-101] }\end{array}$ \\
\hline miR-451 & OS & $\begin{array}{l}\text { Higher expression in pre-treatment samples, corresponded } \\
\text { with positive response to chemotherapy }\end{array}$ & [103] \\
\hline miR-15b & OS & $\begin{array}{l}\text { Higher expression in pre-treatment samples, corresponded } \\
\text { with positive response to chemotherapy }\end{array}$ & [103] \\
\hline miR-125b-1-3p & NB & Lower expression may be associated with chemoresistence & [86] \\
\hline miR-199a-3p & OS & $\begin{array}{l}\text { Differentially expressed in OS cell lines, regulation of } \\
\text { proliferation in osteoblasts, acts as tumour suppressor }\end{array}$ & [96] \\
\hline miR-127-3p & OS & $\begin{array}{l}\text { Differentially expressed in OS cell lines, regulation of } \\
\text { proliferation in osteoblasts, acts as tumour suppressor }\end{array}$ & [96] \\
\hline $\operatorname{miR}-370$ & OS & $\begin{array}{l}\text { Differentially expressed in OS cell lines, regulation of } \\
\text { proliferation in osteoblasts, acts as tumour suppressor }\end{array}$ & [96] \\
\hline $\begin{array}{ll}\text { Let-7 } & \text { Let-7a, Let-7b, Let-7c, Let-7d, } \\
\text { family } & \text { Let-7e, Let-7f, Let-7 g, Let-7i, } \\
& \text { miR-98 }\end{array}$ & WT & $\begin{array}{l}\text { Impaired expression observed due to DICER1 and DROSHA } \\
\text { mutations, regulators of MYCN and LIN28 }\end{array}$ & [28] [113] \\
\hline miR-195 & $\mathrm{HB}$ & $\begin{array}{l}\text { Differentially expressed in fetal subtype compared to } \\
\text { surrounding normal liver tissue }\end{array}$ & [121] \\
\hline miR-210 & $\mathrm{HB}$ & $\begin{array}{l}\text { Differentially expressed in fetal subtype compared to } \\
\text { surrounding normal liver tissue }\end{array}$ & [121] \\
\hline miR-214 & $\mathrm{HB}$ & $\begin{array}{l}\text { Differentially expressed in fetal subtype compared to } \\
\text { surrounding normal liver tissue }\end{array}$ & [121] \\
\hline miR-124 & PA & $\begin{array}{l}\text { Differentially expressed in PA tumours compared to } \\
\text { normal brain tissue, targets putative oncogenes, enriched } \\
\text { in brain tissue }\end{array}$ & [66], [67] \\
\hline miR-218 & $\mathrm{MB}$ & $\begin{array}{l}\text { Low expression observed, targets include pathways involved in } \\
\text { cell cycle, metabolism and motility, CDK6 is target of interest } \\
\text { (upregulates cell cycle progression and blocks differentiation) }\end{array}$ & [71], [72] \\
\hline miR-497 & NB & $\begin{array}{l}\text { Targets key cell cycle regulator WEE1. Low levels seen in high risk } \\
\text { MNA tumours which also display high levels of WEE1. It is a } \\
\text { candidate tumour suppressor and may be useful as a therapeutic target. }\end{array}$ & [85] \\
\hline
\end{tabular}

*NB neuroblastoma, MB medulloblastoma, OS osteosarcoma, WT Wilms Tumour, HB hepatoblastoma, PA pediatric pilocystic astrocytoma

disease and may allow for a better understanding of new opportunities for targeted therapies. Young children are most at risk for developing debilitating late effects from the regimented chemotherapy courses. Through knowledge gained from these studies, we may be able to make better predictions about prognosis.

\section{Embryonal tumours of the brain}

A number of studies in recent times have indicated the frequent involvement of miRNAs in the progression and development of childhood brain tumours, and that this tumour has unique characteristics among rare tumour types. Brain tumours are among the most common cancers in children. The different tumour types and classifcations are generally based on cell structure, composition, growth rate of the tumour and a range of further characteristics. Central nervous system primitive neuroectodermal brain tumours (CNS-PNETs) are a heterogeneous group of CNS neoplasms. These tumours are composed of poorly differentiated neuroepithelial cells and, some variants are associated with aggressive clinical behaviour and poor outcome.

Chromosome 19q13.41 contains the largest human miRNA gene cluster (chromosome 19 miRNA cluster, C19MC); the miRNAs comprising this cluster have been identified as oncogenic [62]. C19MC may drive oncogenic processes in part by facilitating maintenance and transformation of a very early neural compartment [63, 64]. A particularly aggressive group of CNS-PNET tumours demonstrated C19MC amplification with high LIN28 expression. In addition, recent identification of Tweety family member 1 (TTYH1):C19MC gene fusions in embryonal 
tumours with multi-layered rosettes (ETMRs) have been identified and observed to be associated with very high expression of specific miRNAs. ETMRs are a rare and deadly form of paediatric brain tumours, and are characterized by high levels of amplification of C19MC. ETMRs, cell lines and xenografts all demonstrated specific DNA methylation signatures distinct from other tumours and normal tissues, very high overexpression of a previously uncharacterized isoform of $D N M T 3 B$, which originates from an alternative promoter, and which is interestingly only active in the first weeks of neural tube development. This research uncovers a potential oncogenic re-activation of an early developmental signalling program in ETMR via an epigenetic alteration mediated by the brain specific DNMT3B isoform, which has a known embryonic origin [65].

Pediatric pilocystic astrocytoma (PA) is a Word Health Organisation grade I glioma. It is a brain tumour, which often arises in the cerebellum or close to the brainstem in the hypothalamic region or the optic chiasm. However it is possible for it to occur in any location where astrocytes are present (cerebral hemispheres, and the spinal cord). While often these tumours are slow growing and benign, the neoplasms can be cystic and grow very large, causing multiple problems due to the increased intracranial pressure. miRNA profiling has been performed in a group of $43 \mathrm{PA}$ tumours and 5 non-neoplastic brain controls. Differentially expressed miRNAs were identified between PA and normal brain tissue; 13 miRNAs were underexpressed in PA and 20 were over expressed compared to normal brain tissue (Table 1). An example of the importance of a few of these differentially expressed miRNAs is miR-124, which was underexpressed in PA tumours, confirming previous findings. miR-124 targets putative oncogenes, is enriched in brain tissue, and is also found to be downregulated in glioblastomas. miR-124 also has been shown to negatively affect glioblastoma proliferation and migration in vitro [66, 67]. Additionally, upregulation of miR-21 was shown in these tumours and elevation of this miRNA has also been seen in other tumour types, compared with normal tissues (Table 2). An important target of miR-21 is PTEN, a critical suppressor of the PI3K/Akt/ mTOR pathway. Previously PTEN loss had been frequently identified in high-grade gliomas, and decreased levels had been shown in PAs with particularly aggressive histological features. An overall observation of miRNAs in PA is that there are sets of miRNAs underexpressed compared to controls, and alongside this there is increased expression and protein levels of putative oncogenes which may be vital in understanding the biology of PA $[68,69]$.

Ependymal tumours (ET) are the third most common group of brain tumours in children. These tumours comprise four entities; the most common are grade II and grade III, most of which are located in the posterior fossa, with infiltration into vital brain structures. Due to the difficult location of these tumours surgical resection is highly limited. Additionally there are currently no effective prognostic features aside from how accessible they are to surgical intervention. Childhood ependymomas usually don't have genomic imbalances, further making it difficult to establish molecular prognostic features. Recently, however, three miRNAs were demonstrated to differentiate between grade II and III ependymomas. These include miR-17-5p, miR-19a-3p and miR-106b-5p, and the expression of these miRNAs was also significantly correlated with EZH2 expression (a suggested marker for PFA ependymomas). Survival analysis indicated overall and event free survivals were reduced with higher expression levels of miR-17-5p [70].

Medulloblastomas (MBs) are a common brain tumour in children, thought to originate in cerebellar granule neuron progenitors, which have failed to undergo normal cell cycle exit and differentiation. In MB miR-218 expression is downregulated, and low expression of this miRNA has been identified in other cancer types. In addition, reduced expression has been observed in glioma cells [71] (Table 1). Previous research has identified multiple targets of miR-218 that control pathways involved with the cell cycle, cell metabolism and motility. Of those identified, CDK6 is of interest as it has previously been identified as an adverse prognostic marker in $\mathrm{MB}$ because of its role in upregulating cell cycle progression and blocking differentiation [72]. The miR-17-92 cluster is also implicated in MB. Mouse MB models have demonstrated overexpression of several members of the miR-17-92 cluster, three of which, (miR-19a, miR-20, miR-92), were also overexpressed in human MBs with a constitutively activated Sonic Hedgehog signaling pathway, and not in other forms of the disease (Table 2). To explore whether the miR-17-92 cluster could be promoting $\mathrm{MB}$ formation, the expression of these miRNAs was enforced in granule neuron progenitors isolated from cerebella of postnatal day six mouse models (lnk4c-/-; ptch1+/-). These mice formed MBs in orthotopic transplants with complete penetrance, but in similarly engi-

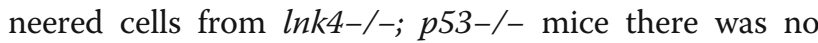
MB formation. These findings point toward a possible functional connection between the miR-17-92 cluster, the Sonic Hedgehog signaling pathway, and the development of MBs in both mice and humans [73].

\section{Neuroblastoma}

Neuroblastoma (NB) is an extracranial solid childhood tumour, and is the most common cancer in infants. The cancer is a neuroendocrine tumour, stemming from neural crest elements of the sympathetic nervous system; it is an ectodermally derived tumour, which reflects its 
Table 2 Summary of miRNAs that are consistently upregulated in different childhood solid tumours

\begin{tabular}{|c|c|c|c|}
\hline miRNA/miRNA cluster & $\begin{array}{l}\text { Childhood cancer } \\
\text { type* }\end{array}$ & Comments & Ref \\
\hline miR-27a & OS & $\begin{array}{l}\text { Higher expression in pre-treatment samples } \\
\text { characterized metastatic disease }\end{array}$ & [103] \\
\hline miR-188-5p & NB & $\begin{array}{l}\text { Higher expression may be associated with } \\
\text { chemoresistance }\end{array}$ & [86] \\
\hline miR-501-5p & NB & $\begin{array}{l}\text { Higher expression may be associated with } \\
\text { chemoresistance }\end{array}$ & [86] \\
\hline miR-135b & OS & $\begin{array}{l}\text { Differentially expressed in OS cell line compared } \\
\text { to normal osteoblast cell line, association with } \\
\text { osteoblast differentiation }\end{array}$ & [91-95] \\
\hline miR-150 & OS & $\begin{array}{l}\text { Differentially expressed in OS cell line compared } \\
\text { to normal osteoblast cell line }\end{array}$ & [91] \\
\hline miR-542-5p & OS & $\begin{array}{l}\text { Differentially expressed in OS cell line compared } \\
\text { to normal osteoblast cell line }\end{array}$ & [91] \\
\hline miR-652 & OS & $\begin{array}{l}\text { Differentially expressed in OS cell line compared } \\
\text { to normal osteoblast cell line }\end{array}$ & [91] \\
\hline miR-181a & OS & $\begin{array}{l}\text { Differentially expressed compared to healthy } \\
\text { bone tissue }\end{array}$ & [103] \\
\hline miR-181b & OS & $\begin{array}{l}\text { Differentially expressed compared to healthy } \\
\text { bone tissue }\end{array}$ & [103] \\
\hline miR-181c & OS & $\begin{array}{l}\text { Differentially expressed compared to healthy } \\
\text { bone tissue }\end{array}$ & [103] \\
\hline miR-492 & $\mathrm{HB}$ & $\begin{array}{l}\text { Elevated levels co-expressed with KRT19, a potential } \\
\text { biomarker for metastatic HB and poor prognosis }\end{array}$ & [120] \\
\hline miR-222 & $H B$ & $\begin{array}{l}\text { Low relative expression associated with increased } \\
\text { overall survival of HB }\end{array}$ & [121] \\
\hline miR-224 & $\mathrm{HB}$ & $\begin{array}{l}\text { Low relative expression associated with increased } \\
\text { overall survival of HB }\end{array}$ & [121] \\
\hline $\operatorname{miR}-221$ & $\mathrm{HB}$ & $\begin{array}{l}\text { Differentially expressed in fetal subtype compared } \\
\text { to surrounding normal liver tissue }\end{array}$ & [121] \\
\hline miR-483-3p & $\mathrm{HB}$ & $\begin{array}{l}\text { High overexpression in tumour specific serum able } \\
\text { to diagnose liver mass }\end{array}$ & [123] \\
\hline miR-205-5p & $H B$ & $\begin{array}{l}\text { High overexpression in tumour specific serum able } \\
\text { to diagnose liver mass }\end{array}$ & [123] \\
\hline $\begin{array}{l}\text { C19MC miR-512-5p, miR-512-3p, miR-1323, miR-498, } \\
\text { miR-520e, miR-515-5p, miR-515-3p, miR-519e-5p, } \\
\text { miR-miR-519e-3p, miR-520f, miR-1283, miR-520a-5p, } \\
\text { miR-520a-3p, miR-526b-5p, miR-526b-3p, miR-519b-5p, } \\
\text { miR-519b-3p, miR-525-5p, miR-525-3p, miR-523-5p, } \\
\text { miR-523-3p, miR-518f-5p, miR-518f-3p, miR-520b }\end{array}$ & CNS-PNET ETMR & $\begin{array}{l}\text { C19MC amplification seen in both CNS-PNET and } \\
\text { ETMRs, miRNA members are considered oncogenic } \\
\text { and may maintain transformation of a very early } \\
\text { neural compartment. } \\
\text { In CNS-PNET C19MC amplification is observed with } \\
\text { high LIN28 expression. } \\
\text { In ETMRs TTYH1:C19MC gene fusions are observed } \\
\text { with very high expression of miRNA members from } \\
\text { this cluster. }\end{array}$ & $\begin{array}{l}{[63],[64],} \\
{[65]}\end{array}$ \\
\hline miR-106b & ET & $\begin{array}{l}\text { Associated with the progression of ET from } \\
\text { grade II to grade III, potential prognostic marker }\end{array}$ & [70] \\
\hline
\end{tabular}

*NB neuroblastoma, OS-osteosarcoma, HB hepatoblastoma, CNS PNET-central nervous system primitive neuro-ectodermal brain tumour, EMTR embryonal tumours with multi-layered rosettes, and $E T$ ependymal tumour

developmentally derived origin [59]. While it frequently originates in one of the adrenal glands, it can also develop in nerve tissues in the neck, chest, abdomen or pelvis [74]. It is a unique and interesting cancer, as it is one of the few malignancies that can demonstrate spontaneous regression from an undifferentiated state to a benign cellular appearance; additionally, there is a large amount of heterogeneity observed in these tumours [75].
Recent work in this area suggests the dysregulation of miRNAs may play an important role in the pathogenesis of NB. For instance, the miR-17-5p-92 cluster of miRNAs, (miR-17-5p, miR-18a, miR-19a, miR-20a and miR-92), is found to be expressed at higher levels in NB cells lines exhibiting overexpression of $M Y C N$ [76]. Tumours with amplification of the MYCN transcription factor and/or loss of the distal chromosome $1 \mathrm{p}$ and gain of $17 \mathrm{q}$ are a 
major genetic subtype of metastatic NB that has a particularly poor prognosis (known as MNA). It has also been demonstrated that $\mathrm{MYCN}$ proteins $\mathrm{c}-\mathrm{Myc} / \mathrm{N}-\mathrm{Myc}$ can bind directly to the promoter of the miR-17-5p-92 cluster, initiating transcription and resulting in the up-regulation of this group of miRNAs from a single transcription unit $[77,78]$. A poor prognosis and therapy resistance is associated with $M Y C N$ amplified NBs. However, previous research has shown that therapy resistant NB can be abolished in vivo using antagomir-17-5p [76].

Components within the miRNA biogenesis pathway have also been implicated in NB, which globally affects miRNA expression. A group of 66 tumours were assessed for a panel of 162 miRNAs using quantitative PCR and low expression of DICER and DROSHA were identified in highrisk tumours. The low expression subsequently accounted for the overall global reduction of miRNA expression observed in the advanced disease state and correlated with a poor outcome for these patients [26]. A global reduction of miRNA expression can be detrimental, and conversely the presence of some miRNAs has been attributed to more positive outcomes, such as the tumour suppressor miR-34a, which is also a critical component of the p53 network [79, 80]. This miRNA has anti-proliferative effects and has been found to target $M Y C N$. miR-34a is located on chromosome 1 and it is not surprising that lower levels are expressed in tumours with/or due to a 1p deletion [81]. This type of deletion is found most often in the MNA type of tumours; a functionally active miR-34a would help to negate the ill effects of the amplification of MYCN. miR-34a is also involved in the regulation of other genes associated with cell proliferation and apoptosis such as E2F3, BCL2, CCND1, and $C D K 6[82,83]$. Since miR-34a plays many roles in controlling and regulating growth, it is obvious disruption of the function of this miRNA would be deleterious and could lead to unrestricted growth leading to cancer development, and indeed miR-34a has been described previously as a tumour suppressor $[79,84]$. Another miRNA that has been reported as a potential tumour suppressor is miR-497; this is due to its action in targeting the key cell cycle regulator WEE1. Expression of miR-497 in MNA tumours is significantly lower than other tumour types, and high WEE1 levels (low miR-497) are significantly associated with poor overall survival and event free survival in NB (Table 1). Additionally, overexpression of miR-497 reduces cell viability and increases apoptosis in MNA cells, and in particular was found to be compatible with an enhanced response to cisplatin. The discovery of the complexity involved in miRNA control has begun to uncover new and promising therapeutic targets for high-risk NB patients [85].

Another common issue seen in childhood solid tumours is chemotherapy resistance; one study investigated drug resistance and expression of miRNAs, and identified several miRNAs of interest in NB chemoresistance models.
Their results confirmed an up-regulation of the expression of miR-188-5p in all three of the chemoresistance models examined; miR-501-5p was found up-regulated, and miR125b-1 was down-regulated in two of the models [86]. These types of investigations are valuable in identifying good miRNA candidates for in-depth exploration to look for novel drug development and perhaps RNAi based therapies for those individuals who are not responding to chemotherapy and may have more aggressive tumour types $[87,88]$.

\section{Osteosarcoma}

Osteosarcoma (OS) is an aggressive malignant neoplasm of the bone that originates in primitive transformed mesenchymal cells [89]. This cancer begins in osteoblasts responsible for forming new bone and is common in adolescents. Bone formation is a dynamic process; orchestrating osteoblast differentiation, which requires precise mechanisms of control, and is particularly critical for both development and growth. OSs tend to occur at the sites of bone growth, and the proliferation occurring at these locations may make the osteoblastic cells more susceptible to acquiring mutations, or other events, which may induce the transformation of cells [90]. Therefore, often the ends of long bones (arms and legs) are affected, although formation in the knee is also a common event.

The molecular etiology of OS remains elusive; miRNAs have been investigated in association with many diseases due to their properties that may allow for widespread effects on development and disease progression. In prior investigations four miRNAs were found to be differentially expressed in OS cell lines compared to normal human osteoblast cell lines [91]. The miRNAs that were overexpressed in the OS cell lines included, miR135b, which has previously been implicated in cancer and is associated with osteoblast differentiation, miR150, miR-542-5p and miR-652 [92-95]. Several miRNAs have been identified that may act as tumour suppressors in OS and are additionally found to be down-regulated in OS cell lines. These miRNAs, (miR-199a-3p, miR127-3p and miR-370), assist with the suppression of oncogenic and anti-apoptotic proteins and also play a role in regulating proliferation of the osteoblasts [96]. As with $\mathrm{NB}$, the miR-34 family is again highlighted as an important regulator of growth signals and acts as a tumour suppressor miRNA. These miRNAs are targeted by $\mathrm{p} 53$ and play a very important part of the tumour suppressor pathway [82, 97-102].

In a recent investigation, a miRNA signature reflecting the pathogenesis of OS was described using surgically procured samples from human patients [103]. These samples highly expressed miR-181a, miR-181b and miR$181 \mathrm{c}$ and also showed reduced expression of miR-16, 
miR-29b and miR-142-5p. However, it is noteworthy this study also identified valuable pre-treatment biomarkers of metastasis and indicators of responsiveness to therapy. The biomarkers and indicators of metastatic development risk included a higher expression of miR-27a and miR-181c-3p in the pre-treatment samples. This characterised patients who went on to develop metastastic lesions. Furthermore, higher expression of miR-451 and miR-15b in pre-treatment samples correlated with positive responses to chemotherapy [103].

\section{Wilms tumour}

Wilms tumour (WT), or nephroblastoma is a solid tumour occurring in the kidneys of children. Embryonal renal neoplasms are thought to develop in nephrogenic rests (NRs) with morphological and molecular analogies to kidney development. Most commonly WTs are unilateral with a single tumour affecting the kidney. However multiple tumours can arise in one of the kidneys, or the cancer may occur bilaterally in both kidneys [104, 105].

In WT relatively few driver genes have been identified [106]. Recently both Sanger sequencing and whole exome sequencing have provided the means to identify mutations in critical elements of the miRNA processing machinery in WT patients. Several recent studies have uncovered miRNA biogenesis disruptions in WT, which provides an excellent starting point for research in this area [27, 28, 107]. Rakheja and colleagues investigated the presence of these potential mutations in 44 WT samples using whole-exome sequencing [28]. In addition to identifying novel mutations in MYCN, SMARCA4 and $A R I D 1 A$, missense mutations were discovered in the miRNA processing enzymes DROSHA and DICER1. Further examination of tumour miRNA expression using in vitro processing assays and genomic editing of cell lines demonstrated that these mutations in DROSHA and DICER1 greatly influence miRNA processing and likely cause down regulation in mature miRNAs, which generate an altered miRNA expression profile in these WT patients. Further, there were distinct mechanisms also identified; DICER1 RNase IIIB mutations preferentially affected the processing of miRNAs derived from the 5 , arm of pre-miRNA hairpins. Conversely DROSHA RNase IIIB mutations were found to cause global inhibition of miRNA biogenesis through a dominant-negative mechanism. Mutations in these enzymes also impaired the expression of tumour suppressor miRNAs such as the let-7 family; this is an important regulator of genes such as MYCN, LIN28 as well as other previously identified WT oncogenes [28]. Downregulation of certain miRNAs in WT were also observed to have a major affect on critical pathways that are involved in kidney development, such as, TGF- $\beta$. For example Activin A receptor type $2 \mathrm{~B}$ (ACVR2B), an important component of the TGF- $\beta$ pathway, is often highly expressed in renal neoplasms; several miRNAs have been noted as downregulated and have been confirmed to directly target this gene (Table 1). This investigation was the first to implicate the TGF- $\beta$ pathway in the pathogenesis of WT [108].

A number of up regulated miRNAs were also identified in WT; up-regulation of miR-17-5p, miR-18a, miR19b, miR-92 and miR-20a was reported in WT compared to other kidney tumours or normal kidney tissues [109]. This is of interest, because the cluster (miR-17-5p-92) was also identified as being up-regulated in the subtype of NB known as MNA [76] (Table 3). As mentioned, these miRNAs are thought to contribute to tumour progression and metastasis in the later stages of the cancer $[103,110]$. Other miRNAs found to be upregulated in WT have been investigated for being able to distinguish the different subtypes of WT and for giving an indication on severity of disease, or for influencing important factors such as endothelial to mesenchymal transitions (EMT) and chemosensitivity [111]. Another mechanism recently recognised in the development of WT is the aberrant regulation of miRNA Let-7 through overexpression of LIN28 [112]. Let-7 is a direct target of LIN28, and it is a potent regulator of stem cell self-renewal and differentiation. A murine model has shown that directed overexpression of both LIN28A and LIN28B in the renal lineage results in the formation of WTs [113]. Further investigation of LIN28 expression in mutant mice revealed that terminal differentiation only occurred in nephron progenitor cells after LIN28 had been completely withdrawn. It is plausible that the overexpression of LIN28 may cause an imbalance in proliferation and differentiation in these specific cells, rather than a complete blockage of differentiation, resulting in the formation of these types of tumours $[113,114]$.

\section{Hepatoblastoma}

Hepatoblastoma ( $\mathrm{HB})$ is a relatively rare disease, although it is the most common childhood liver cancer. It is often diagnosed as an asymptomatic abdominal mass [115]. The most commonly affected age group are infants between six months and three years of age. The majority of $\mathrm{HB}$ cases are sporadic. However, HB may occur in conjunction with a developmental syndrome such as Beckwith-Wiedemann Syndrome (BWS) and Familial Adenomatous Polyposis (FAP) [116, 117].

Since $\mathrm{HB}$ is a rare cancer, research is challenging and often relies on formalin fixed paraffin embedded (FFPE) samples, which are known to provide obstacles in the extraction of total RNA due to degradation. However, recent research has demonstrated miRNA expression is relatively stable and well preserved in these valuable archival samples which is an important factor for future research in this field 
Table 3 Summary of miRNAs that are either up or down regulated or contains conflicting evidence of expression in childhood solid tumours

\begin{tabular}{|c|c|c|c|c|}
\hline miRNA/miRNA clu & ster & Childhood cancer type $^{*}$ & Comments & Ref \\
\hline \multirow[t]{5}{*}{ miR-17-92 cluster } & \multirow{5}{*}{$\begin{array}{l}\text { miR-17-5p, miR-18a, } \\
\text { miR-19a, miR-19b, } \\
\text { miR-20a, miR-92 }\end{array}$} & NB, WT, MB, ET (upregulated) & $\begin{array}{l}\text { c-Myc/n-Myc bind to increase expression in } \\
\text { MYCN amplified NB }\end{array}$ & \multirow[t]{5}{*}[70,76-78,109,121]{} \\
\hline & & \multirow[t]{4}{*}{ HB (downregulated) } & $\begin{array}{l}\text { Upregulation in WT compared to other kidney } \\
\text { tumours or normal tissue }\end{array}$ & \\
\hline & & & $\begin{array}{l}\text { Lower expression of miR-17-5p in fetal subtype } \\
\text { of HB compared to surrounding non-tumourous } \\
\text { liver tissue }\end{array}$ & \\
\hline & & & $\begin{array}{l}\text { Overexpressed in mouse MB models and human } \\
\text { MBs (some with constitutively activated Sonic } \\
\text { Hedgehog signalling) }\end{array}$ & \\
\hline & & & $\begin{array}{l}\text { High levels of expression of miR-17-5p and } \\
\text { miR-19a-3p associate with grade III (advancement) } \\
\text { in ET }\end{array}$ & \\
\hline \multirow{2}{*}{\multicolumn{2}{|c|}{ miR-21 }} & HB (Downregulated) & $\begin{array}{l}\text { High relative expression associated with increased } \\
\text { overall survival of HB }\end{array}$ & \multirow[t]{2}{*}{ [121] } \\
\hline & & PA (upregulated) & $\begin{array}{l}\text { Upregulation seen in PA with more aggressive } \\
\text { histological features, an important target is PTEN }\end{array}$ & \\
\hline \multirow[t]{2}{*}{ miR-122-5p } & & $\begin{array}{l}\text { HB (upregulated, } \\
\text { dowregulated) }\end{array}$ & $\begin{array}{l}\text { miR-21 was detected in higher levels in } \mathrm{HB} \text { patients } \\
\text { in both the plasma and exosomes compared to } \\
\text { control patients. }\end{array}$ & \multirow[t]{2}{*}[25,122-124]{} \\
\hline & & & $\begin{array}{l}\text { Low expression of miR-122-5p is seen in the embryonal } \\
\text { subtype of HB. Serum miRNA profiles of HB patients } \\
\text { indicated high expression of miR-122-5p and could be } \\
\text { used in a panel to perform a non-invasive differential } \\
\text { diagnosis of liver mass. }\end{array}$ & \\
\hline
\end{tabular}

${ }^{*}$ NBneuroblastoma, MBmedulloblastoma, WT Wilms' Tumour, HB hepatoblastoma, PA pediatric pilocystic astrocytoma, and ET ependymal tumour

$[118,119]$. Previous studies provided evidence for a few prognostic miRNAs associated with $\mathrm{HB}$, such as miR-492, which is a potential biomarker in metastatic HB. Overexpression of pleiomorphic adenoma gene 1 (PLAG1) has been characterised in $\mathrm{HB}$, and has been demonstrated through RNA interference analysis combined with miRNA arrays to strongly influence miR-492. Additionally, it was revealed that miR-492 could originate from the coding sequence of the $\mathrm{HB}$ marker gene keratin 19 (KRT19). Significantly elevated levels of coexpressed KRT19 and miR-492 were identified in metastatic HB tumour samples [120]. This is of interest as metastatic HB is often associated with poor prognosis. Indeed, miR-492 and its associated targets may provide biomarkers or inform on targeted therapies [120].

Other potential prognostic miRNAs have been identified in a recent study, which showed that histological subtypes of a group of 20 tumour samples did not correlate with survival. However this investigation did identify that the levels of several miRNAs were independently prognostic for $\mathrm{HB}$ with significantly increased overall survival. These miRNAs included the high relative expression of miR-21 and low relative expression of miR-222 and miR-224 [121] (Tables 2 and 3). In a recent study miR-21 was examined for its potential role as a diagnostic/prognostic indicator in peripheral blood where it has been reported to be relatively stable within protective exosomes or nanovesicles. Exosomes, which can be released in large amounts from tumour cells due to a hypoxic environment and other internal changes, are of interest because a blood sample is a less invasive method for diagnosis and prognosis for the patient. Blood samples were prepared retrospectively in 32 Chinese hepatoblastoma patients and healthy controls; the blood samples were separated to isolate RNA directly from the exosomes present in the sample (which precipitate at the bottom), while also preparing exosomedepleted samples (using the supernatant of the same sample). The concentration of miR-21 in the exosomes prepared from blood of $\mathrm{HB}$ patients was significantly higher than in exosome-depleted supernatants and whole plasma. The expression of miR-21 detected in $\mathrm{HB}$ children was significantly higher in both the plasma and exosomes when compared to controls. Additionally, exosomal miR-21 is not only an independent predictor of event-free survival for patients, it also was more accurate in diagnosing $\mathrm{HB}$ than alpha-fetoprotein levels (AFP), the traditional means of $\mathrm{HB}$ diagnosis [122]. There were also miRNAs identified with unique expression levels in both fetal and embryonal subtypes in comparison with surrounding non-tumorous liver tissues. In the fetal subtype of samples, there was a lower expression compared 
to surrounding normal liver tissue in miRNAs miR-175p, miR-195, miR-210 and miR-214, while higher expression was observed in miR-221 (Tables 1, 2 and 3). In the embryonal subtype of $\mathrm{HB}$ a lower expression of miR122-5p was demonstrated. Loss of miR-122-5p is also frequent in hepatocellular carcinoma $(\mathrm{HCC})$ and has been correlated with migration, invasion, and in vivo tumorigenesis. miR-122-5p is also considered a differentiation marker for hepatocytes. Lower miR-122-5p expression levels indicated in the embryonal subtype is in agreement with the lower degree of differentiation found in early embryonal development. In a recent comprehensive investigation of 33 different types of childhood solid tumours and 20 control cases, serum miRNA profiles were examined. Four HB samples were included in this group of tumours and tumour specific serum miRNA profiles were determined for each specific tumour type. Using the panel of miRNAs identified for HB, (high overexpression of miR-483-3p, miR-205-5p, and miR122-5p), a non-invasive differential diagnosis of a liver mass could be performed when compared to tumour mixed samples of neuroblastomas (MYCN-amplified and others) [25]. It is of interest that contradicting results from two studies identified miR-122-5p as being of interest, except at opposite ends of the spectrum, (one observing lower relative expression and the other stating the miRNA to be in the top ten of the highest relative overexpression) (Table 3). It is important to acknowledge that in serum miRNA profiling investigations only four $\mathrm{HB}$ samples were investigated, and in addition the authors pointed out that miR-122-5p was found in increased levels in non-HB samples in this study, such as in pancreatic pleiomorphic rhadomyosarcoma (RMS) presenting with obstructive jaundice [25]. Serum levels of miR-122-5p were increased, while the expression of miR-122-5p was reduced in liver tissue, which could be due to passive miRNA drainage from tumour cells, as has been observed in other tumours [123]. Expression of miR-122-5p has been identified as a non-specific marker of liver damage, and is increased in the serum of jaundiced patients [124]. These studies highlight the importance of identifying miRNA profiles (in tumour tissue and in serum), and shows that there may be specific miRNAs with unique roles in various types of childhood solid tumours.

\section{Conclusions}

The role of miRNAs in the regulation of critical signalling pathways such as Wnt/ $\beta$-catenin, Notch, and TGF $\beta / B M P$, has emerged as an important area in the exploration of childhood cancer development. Childhood solid tumours often display heterogeneous embryonic features, pointing to an early origin of tumourigenesis. While research into miRNA expression at very early stages of embryonic development (preimplantation) is largely unexplored at this stage, there is evidence that miRNAs regulate key components of several developmental pathways following these stages, and that expression of miRNAs directs development and differentiation of specific cells and tissues, which becomes more complex as the embryo continues to develop (Fig. 1). If disruptions occur to the network of regulatory connections between miRNAs and developmental signalling pathways, then this may lead to incorrect maintenance of signalling, promoting an environment where proliferation is enhanced, and cells are able to evade apoptosis, or remain in a more pluripotent state. In this instance the normal growth regulatory processes have lost control, or are mis-timed, and therefore may initiate tumour growth.

In the childhood tumour types discussed above, there are miRNAs (or clusters) that are clearly implicated in more than one type of tumour (Tables 1, 2 and 3). Identifying key miRNAs, which act as tumour suppressors, or as oncomiRs, is already a growing area of interest, but the discovery of a common miRNA regulated mechanism throughout all childhood solid tumours would be immensely valuable in identifying new targeted therapies [125]. The miR-17-92 cluster is implicated in several childhood solid tumours and is highlighted in this review in NB, WT, HB and MB; it is a well-researched topic and is known to be vital in early development [126]. Members of the cluster have been found to be ubiquitously expressed in all tissues (except the heart and blood vessels) in early chick embryos, which would suggest these miRNAs play a role in regulating baseline processes that are critical in many different cell and tissue types. The shared expression of this group of miRNAs is an interesting phenomenon and could potentially hold promising targets for the development of new therapies in treating childhood solid tumours [127]. Another set of miRNAs worth further investigation, which are implicated in several paediatric tumours, is the C19MC group (Table 2). The miRNAs in this cluster are also thought to be oncogenic, and appear to be closely linked to early neural tube development, and may act in promoting transformation and maintenance of these early proliferative cell types. The C19MC group appears to be especially critical in the formation of embryonal brain tumours, particularly those with aggressive histology. It would be worth determining if this cluster is active in other childhood solid tumours, or if it is brain specific.

It is critical to uncover the mechanisms by which aberrant developmental signalling occurs and how these processes may be manipulated to regress into a more regulated path without causing additional disruption in embryonic development. Since these events may occur very early, it has thus far been challenging to study miRNA expression in embryo preimplantation. However, miRNA expression in the stages following implantation, 
at the beginning of embryonic development, is vital and has been widely researched. The discovery of miRNAs themselves were uncovered in the investigation of developmental timing in C. elegans [1].

While it is hopeful that elucidation of how miRNAs contribute to the formation of solid tumours can help revolutionise the approach to treating patients, it adds yet another layer of complexity to an already entangled web of interactions occurring both at the genetic and epigenetic level. Currently there are over 2,500 mature human miRNA products identified in humans [128]. Given that each miRNA is able to target tens or even hundreds of different genes, the development of targeted therapies will be difficult, and due to the nature of miRNAs and their ability to be "flexible" in base pair complementarity to their targets, it seems that if specific miRNAs were targeted therapeutically, it might give rise to a compensatory effect from other related miRNAs [129]. In addition, often members of the same family of miRNAs tend to target shared transcripts; this is due to the similarities in the seed region. At the current time communities of miRNAs are still being discovered that share a significant proportion of target genes through co-expression analyses, and therefore there is still much to be uncovered about the integrated functional categories of different miRNAs and how they interact [130]. Ideally, uncovering the initiating events in miRNA expression, (when the first miRNAs are expressed in development and how this takes place), would help inform on how disruptions may occur and allow researchers to strive toward better classification of the contributions of miRNAs in embryonal solid tumours. However, it remains that the number of investigations in the different types of childhood solid tumours are still relatively few; translation of this research into miRNAs, or their upstream counterparts is poised to expand to other solid tumours. This will assist in uncovering highly valuable links between different kinds of tumours. In the future these discoveries may form the basis to develop a type of shared network of miRNAs or specific mutations in biogenesis pathway components that could help in the customisation of current therapeutic treatments, or even the generation of new, targeted therapies.

\section{Abbreviations}

BMP: bone morphogenetic protein; BWS: Beckwith - Wiedemann syndrome; C19MC: Chromosome 19 microRNA cluster; CNS-PNET: Central nervous system primitive neuro-ectodermal brain tumour; COO: Cell of origin;

CSC: Cancer stem cell; ETMR: Embryonal tumours with multi-layered rosettes; FAP: Familial adenomatous polyposis; HB: Heptaoblastoma; JAK/STAT: Janusactivated kinase/signal transducer and activator of transcription;

KRT19: Keratin 19; MAPK: Mitogen-activated protein kinase;

MB: Medulloblastoma; miRISC: Microrna induced silencing complex;

miRNA: Micrornas; MRE: Microrna recognition elements; NB: Neuroblastoma; oncomiR: Oncogenic microRNAs; OS: Osteosarcoma; PA: Pediatric pilocystic astrocytoma; PI3K: Phosphatidylinositol; PLAG1: Pleomorphic adenoma gene; TGF: Transforming growth factor; TYYH1: Tweety family member 1; WT: Wilms Tumour

\section{Acknowledgements}

We are grateful to the Children's Cancer Research Trust, New Zealand for providing funding to support this research. MRE and AC were supported by the University of Otago Leading Thinkers Advancement Campaign, and the New Zealand Institute for Cancer Research Trust (NZICRT), respectively.

\section{Funding}

Children's Cancer Research Trust, New Zealand, University of Otago Leading Thinkers Advancement Campaign, and New Zealand Institute for Cancer Research Trust (NZICRT).

\section{Availability of data and materials}

Not applicable.

\section{Authors' contributions}

AC, MRE, MJS and ALL all contributed in developing the scope and depth of the manuscript. ALL wrote the manuscript with assistance from AC and MRE in editing. MJS provided feedback and suggestions for the direction of the material. ALL made the figures with intellectual input from AC and MRE. All authors read and approved the final manuscript.

\section{Competing interests}

The authors declare they have no competing interests.

\section{Consent for publication}

Not applicable.

Ethics approval and consent to participate

Not applicable.

\section{Author details}

'Department of Pathology, Dunedin School of Medicine, University of Otago, 56 Hanover Street, P.O. Box 913, Dunedin 9016, New Zealand. ${ }^{2}$ Maurice Wilkins Centre for Molecular Biodiscovery, Level 2, 3A Symonds Street, Auckland, New Zealand. ${ }^{3}$ Royal Children's Hospital, Melbourne, VIC, Australia.

Received: 20 July 2016 Accepted: 4 January 2017

Published online: 19 January 2017

\section{References}

1. Lee RC, Feinbaum RL, Ambros V. The C. elegans heterochronic gene lin-4 encodes small RNAs with antisense complementarity to lin-14. Cell. 1993; 75(5):843-54.

2. Kozomara A, Griffiths-Jones S. miRBase: annotating high confidence microRNAs using deep sequencing data. Nucleic Acids Res. 2014;42(D1): D68-73.

3. Gregory T. Coincidence, coevolution, or causation? DNA content, cellsize, and the C-value enigma. Biol Rev. 2001;76(1):65-101.

4. Ohno S: So much "junk" DNA in our genome. In: Brookhaven Symp Biol. New York: Gordon \& Breach; 1972. p. 366-70.

5. Lopez-Serra P, Esteller M. DNA methylation-associated silencing of tumorsuppressor microRNAs in cancer. Oncogene. 2012;31(13):1609-22.

6. Djebali S, Davis CA, Merkel A, Dobin A, Lassmann T, Mortazavi A, Tanzer A, Lagarde J, Lin W, Schlesinger F, et al. Landscape of transcription in human cells. Nature. 2012;489(7414):101-8.

7. Gerstein MB, Kundaje A, Hariharan M, Landt SG, Yan KK, Cheng C, Mu XJ, Khurana E, Rozowsky J, Alexander R, et al. Architecture of the human regulatory network derived from ENCODE data. Nature. 2012:489(7414):91-100.

8. Carthew RW, Sontheimer EJ. Origins and Mechanisms of miRNAs and siRNAs. Cell. 2009;136(4):642-55.

9. Lagos-Quintana M, Rauhut R, Yalcin A, Meyer J, Lendeckel W, Tuschl T. Identification of tissue-specific microRNAs from mouse. Curr Biol. 2002;12(9):735-9.

10. Wienholds E, Kloosterman WP, Miska E, Alvarez-Saavedra E, Berezikov E, de Bruijn E, Horvitz HR, Kauppinen S, Plasterk RH. MicroRNA expression in zebrafish embryonic development. Science. 2005;309(5732):310-1.

11. Volinia S, Calin GA, Liu CG, Ambs S, Cimmino A, Petrocca F, Visone R, lorio $M$, Roldo $C$, Ferracin $M$, et al. A microRNA expression signature of human solid tumors defines cancer gene targets. Proc Natl Acad Sci U S A. 2006; 103(7):2257-61. 
12. Hossain A, Kuo MT, Saunders GF. Mir-17-5p regulates breast cancer cell proliferation by inhibiting translation of AIB1 mRNA. Mol Cell Biol. 2006; 26(21):8191-201.

13. O'Donnell KA, Wentzel EA, Zeller Kl, Dang CV, Mendell JT. c-Myc-regulated microRNAs modulate E2F1 expression. Nature. 2005;435(7043):839-43.

14. Chen JF, Mandel EM, Thomson JM, Wu Q, Callis TE, Hammond SM, Conlon FL, Wang DZ. The role of microRNA-1 and microRNA-133 in skeletal muscle proliferation and differentiation. Nat Genet. 2006;38(2):228-33.

15. Wood LD, Parsons DW, Jones S, Lin J, Sjoblom T, Leary RJ, Shen D, Boca SM, Barber T, Ptak J, et al. The genomic landscapes of human breast and colorectal cancers. Science. 2007;318(5853):1108-13.

16. Venturini L, Battmer $K$, Castoldi M, Schultheis B, Hochhaus A, Muckenthaler MU, Ganser A, Eder M, Scherr M. Expression of the miR-17-92 polycistron in chronic myeloid leukemia (CML) CD34+ cells. Blood. 2007:109(10):4399-405.

17. Dews M, Homayouni A, Yu D, Murphy D, Sevignani C, Wentzel E, Furth EE, Lee WM, Enders GH, Mendell JT, et al. Augmentation of tumor angiogenesis by a Myc-activated microRNA cluster. Nat Genet. 2006;38(9):1060-5.

18. Sylvestre Y, De Guire V, Querido E, Mukhopadhyay UK, Bourdeau V, Major F, Ferbeyre G, Chartrand P. An E2F/miR-20a autoregulatory feedback loop. J Biol Chem. 2007:282(4):2135-43.

19. Hayashita Y, Osada H, Tatematsu Y, Yamada H, Yanagisawa K, Tomida S, Yatabe $Y$, Kawahara K, Sekido Y, Takahashi T. A polycistronic microRNA cluster, miR-17-92, is overexpressed in human lung cancers and enhances cell proliferation. Cancer Res. 2005;65(21):9628-32.

20. Hanahan D, Weinberg RA. Hallmarks of cancer: the next generation. Cell. 2011;144(5):646-74.

21. Baylin SB, Jones PA. A decade of exploring the cancer epigenome - biological and translational implications. Nat Rev Cancer. 2011;11(10):726-34.

22. Sandoval J, Esteller M. Cancer epigenomics: beyond genomics. Curr Opin Genet Dev. 2012;22(1):50-5.

23. Palmer RD, Murray MJ, Saini HK, van Dongen S, Abreu-Goodger C, Muralidhar B, Pett MR, Thornton CM, Nicholson JC, Enright AJ. Malignant germ cell tumors display common microRNA profiles resulting in global changes in expression of messenger RNA targets. Cancer Res. 2010;70(7):2911-23.

24. Lu J, Getz G, Miska EA, Alvarez-Saavedra E, Lamb J, Peck D, Sweet-Cordero A, Ebert BL, Mak RH, Ferrando AA, et al. MicroRNA expression profiles classify human cancers. Nature. 2005:435(7043):834-8.

25. Murray MJ, Raby KL, Saini HK, Bailey S, Wool SV, Tunnacliffe JM, Enright AJ, Nicholson JC, Coleman N. Solid tumors of childhood display specific serum microRNA profiles. Cancer epidemiology, biomarkers \& prevention : a publication of the American Association for Cancer Research, cosponsored by the American Society of Preventive Oncology. 2015;24(2):350-60.

26. Lin R-J, Lin Y-C, Chen J, Kuo H-H, Chen Y-Y, Diccianni MB, London WB, Chang $\mathrm{C}-\mathrm{H}$, Alice LY. microRNA signature and expression of Dicer and Drosha can predict prognosis and delineate risk groups in neuroblastoma. Cancer Res. 2010;70(20):7841-50.

27. Torrezan GT, Ferreira EN, Nakahata AM, Barros BD, Castro MT, Correa BR, Krepischi AC, Olivieri EH, Cunha IW, Tabori U: Recurrent somatic mutation in DROSHA induces microRNA profile changes in Wilms tumour. Nat Commun. 2014:5:4039.

28. Rakheja D, Chen KS, Liu Y, Shukla AA, Schmid V, Chang T-C, Khokhar S, Wickiser JE, Karandikar NJ, Malter JS: Somatic mutations in DROSHA and DICER1 impair microRNA biogenesis through distinct mechanisms in Wilms tumours. Nat Commun. 2014;2:4802.

29. Sanchez-Diaz PC, Hsiao T-H, Chang JC, Yue D, Tan MC, Chen H-IH, Tomlinson GE, Huang Y, Chen Y, Hung JY. De-regulated microRNAs in pediatric cancer stem cells target pathways involved in cell proliferation, cell cycle and development. PLoS One. 2013;8(4):e61622

30. Scotting PJ, Walker DA, Perilongo G. Childhood solid tumours: a developmental disorder. Nat Rev Cancer. 2005;5(6):481-8.

31. Lee $Y$, Jeon K, Lee JT, Kim S, Kim VN. MicroRNA maturation: stepwise processing and subcellular localization. EMBO J. 2002;21(17):4663-70.

32. Zeng $Y$, Cullen BR. Sequence requirements for micro RNA processing and function in human cells. RNA. 2003;9(1):112-23.

33. Lee Y, Ahn C, Han J, Choi H, Kim J, Yim J, Lee J, Provost P, Radmark O, Kim $\mathrm{S}$, et al. The nuclear RNase III Drosha initiates microRNA processing. Nature. 2003:425(6956):415-9.

34. Basyuk E, Suavet F, Doglio A, Bordonne R, Bertrand E. Human let-7 stemloop precursors harbor features of RNase III cleavage products. Nucleic Acids Res. 2003;31(22):6593-7.
35. Yi R, Qin Y, Macara IG, Cullen BR. Exportin-5 mediates the nuclear export of pre-microRNAs and short hairpin RNAs. Genes Dev. 2003;17(24):3011-6.

36. Lund E, Guttinger S, Calado A, Dahlberg JE, Kutay U. Nuclear export of microRNA precursors. Science. 2004;303(5654):95-8.

37. Lau NC, Lim LP, Weinstein EG, Bartel DP. An abundant class of tiny RNAs with probable regulatory roles in Caenorhabditis elegans. Science. 2001; 294(5543):858-62

38. Hammond SM, Bernstein E, Beach D, Hannon GJ. An RNA-directed nuclease mediates post-transcriptional gene silencing in Drosophila cells. Nature. 2000;404(6775):293-6.

39. Elbashir SM, Lendeckel W, Tuschl T. RNA interference is mediated by 21and 22-nucleotide RNAs. Genes Dev. 2001;15(2):188-200.

40. Nykanen A, Haley B, Zamore PD. ATP requirements and small interfering RNA structure in the RNA interference pathway. Cell. 2001;107(3):309-21.

41. Martinez J, Patkaniowska A, Urlaub H, Luhrmann R, Tuschl T. Single-stranded antisense siRNAs guide target RNA cleavage in RNAi. Cell. 2002;110(5):563-74

42. Brennecke J, Stark A, Russell RB, Cohen SM. Principles of microRNA-target recognition. PLoS Biol. 2005;3(3):e85.

43. Chou CH, Chang NW, Shrestha S, Hsu SD, Lin YL, Lee WH, Yang CD, Hong HC, Wei TY, Tu SJ, et al. miRTarBase 2016: updates to the experimentally validated miRNA-target interactions database. Nucleic Acids Res. 2016:44(D1):D239-247.

44. Friedman RC, Farh KK, Burge CB, Bartel DP. Most mammalian mRNAs are conserved targets of microRNAs. Genome Res. 2009:19(1):92-105.

45. Graves P, Zeng Y. Biogenesis of mammalian microRNAs: a global view. Genomics, proteomics \& bioinformatics. 2012;10(5):239-45.

46. Lal A, Navarro F, Maher CA, Maliszewski LE, Yan N, O'Day E, Chowdhury D, Dykxhoorn DM, Tsai P, Hofmann O, et al. miR-24 Inhibits cell proliferation by targeting E2F2, MYC, and other cell-cycle genes via binding to "seedless" 3'UTR microRNA recognition elements. Mol Cell. 2009;35(5):610-25.

47. Zhang $Y$, Yang Z, Wu J. Signaling pathways and preimplantation development of mammalian embryos. FEBS J. 2007;274(17):4349-59.

48. Bernstein E, Kim SY, Carmell MA, Murchison EP, Alcorn H, Li MZ, Mills AA, Elledge SJ, Anderson KV, Hannon GJ. Dicer is essential for mouse development. Nat Genet. 2003;35(3):215-7.

49. Johnson SM, Grosshans H, Shingara J, Byrom M, Jarvis R, Cheng A, Labourie $E$, Reinert KL, Brown D, Slack FJ. RAS is regulated by the let-7 microRNA family. Cell. 2005;120(5):635-47.

50. Lehmann U, Hasemeier B, Christgen M, Müller M, Römermann D, Länger F, Kreipe $\mathrm{H}$. Epigenetic inactivation of microRNA gene hsa-mir-9-1 in human breast cancer. J Pathol. 2008:214(1):17-24.

51. Chatterjee A, Eccles MR. DNA methylation and epigenomics: new technologies and emerging concepts. Genome Biol. 2015;16(1):103.

52. Suzuki H, Maruyama R, Yamamoto E, Kai M. DNA methylation and microRNA dysregulation in cancer. Mol Oncol. 2012;6(6):567-78.

53. Calle EE, Rodriguez C, Walker-Thurmond K, Thun MJ. Overweight, Obesity, and Mortality from Cancer in a Prospectively Studied Cohort of U.S. Adults. N Engl J Med. 2003;348(17):1625-38.

54. Sugiyama A, Maruta F, Ikeno T, Ishida K, Kawasaki S, Katsuyama T, Shimizu N, Tatematsu M. Helicobacter pylori infection enhances $\mathrm{N}$-methyl- $\mathrm{N}$ nitrosourea-induced stomach carcinogenesis in the Mongolian gerbil. Cancer Res. 1998:58(10):2067-9.

55. Vineis $P$, Alavanja M, Buffler P, Fontham E, Franceschi S, Gao YT, Gupta PC, Hackshaw A, Matos E, Samet J, et al. Tobacco and Cancer: Recent Epidemiological Evidence. J Natl Cancer Inst. 2004;96(2):99-106.

56. Grimmer MR, Weiss WA. Childhood tumors of the nervous system as disorders of normal development. Curr Opin Pediatr. 2006;18(6):634-8.

57. Cairo S, Armengol C, De Reyniès A, Wei Y, Thomas E, Renard C-A, Goga A, Balakrishnan A, Semeraro M, Gresh L, et al. Hepatic Stem-like Phenotype and Interplay of Wnt/ $\beta$-Catenin and Myc Signaling in Aggressive Childhood Liver Cancer. Cancer Cell. 2008;14(6):471-84.

58. Lawlor ER, Thiele CJ. Epigenetic Changes in Pediatric Solid Tumors: Promising New Targets. Clin Cancer Res. 2012;18(10):2768-79.

59. Stewart E, Federico S, Karlstrom A, Shelat A, Sablauer A, Pappo A, Dyer MA. The Childhood Solid Tumor Network: A new resource for the developmental biology and oncology research communities. Dev Biol. 2016;411(2):287-93.

60. Steenman M, Westerveld A, Mannens M. Genetics of Beckwith-Wiedemann syndrome-associated tumors: common genetic pathways. Genes Chromosomes Cancer. 2000;28(1):1-13.

61. Liu X, Fu Q, Du Y, Yang Y, Cho WC. MicroRNA as Regulators of Cancer Stem Cells and Chemoresistance in Colorectal Cancer. Curr Cancer Drug Targets. 2016;16(9):738-54 
62. Vaira V, Elli F, Forno I, Guarnieri V, Verdelli C, Ferrero S, Scillitani A, Vicentin $\mathrm{L}$, Cetani F, Mantovani G. The microRNA cluster C19MC is deregulated in parathyroid tumours. J Mol Endocrinol. 2012;49(2):115-24.

63. Spence T, Sin-Chan P, Picard D, Barszczyk M, Hoss K, Lu M, Kim S-K, Ra Y-S, Nakamura H, Fangusaro J. CNS-PNETs with C19MC amplification and/or LIN28 expression comprise a distinct histogenetic diagnostic and therapeutic entity. Acta Neuropathol. 2014;128(2):291-303.

64. Li M, Lee KF, Lu Y, Clarke I, Shih D, Eberhart C, Collins VP, Van Meter T, Picard D, Zhou L. Frequent amplification of a chr19q13. 41 microRNA polycistron in aggressive primitive neuroectodermal brain tumors. Cancer Cell. 2009;16(6):533-46.

65. Kleinman CL, Gerges N, Papillon-Cavanagh S, Sin-Chan P, Pramatarova A, Quang D-AK, Adoue V, Busche S, Caron M, Djambazian H. Fusion of TTYH1 with the C19MC microRNA cluster drives expression of a brain-specific DNMT3B isoform in the embryonal brain tumor ETMR. Nat Genet. 2014;46(1):39-44.

66. Li D, Chen P, Li X-Y, Zhang L-Y, Xiong W, Zhou M, Xiao L, Zeng F, Li X-L, Wu $\mathrm{M}-\mathrm{H}$. Grade-specific expression profiles of miRNAs/mRNAs and docking study in human grade I-III astrocytomas. Omics: a journal of integrative biology. 2011;15(10):673-82.

67. Silber J, Lim DA, Petritsch C, Persson Al, Maunakea AK, Yu M, Vandenberg SR, Ginzinger DG, James CD, Costello JF. miR-124 and miR-137 inhibit proliferation of glioblastoma multiforme cells and induce differentiation of brain tumor stem cells. BMC medicine. 2008;6(1):14.

68. Birks DK, Barton VN, Donson AM, Handler MH, Vibhakar R, Foreman NK. Survey of MicroRNA expression in pediatric brain tumors. Pediatr Blood Cancer. 2011:56(2):211-6

69. Ho C-Y, Bar E, Giannini C, Marchionni L, Karajannis MA, Zagzag D, Gutmann $\mathrm{DH}$, Eberhart CG, Rodriguez FJ. MicroRNA profiling in pediatric pilocytic astrocytoma reveals biologically relevant targets, including PBX3, NFIB, and METAP2. Neuro-Oncology. 2013;15(1):69-82

70. Zakrzewska M, Fendler W, Zakrzewski K, Sikorska B, Grajkowska W, Dembowska-Bagińska B, Filipek I, Stefańczyk Ł, Liberski PP. Altered MicroRNA Expression Is Associated with Tumor Grade, Molecular Background and Outcome in Childhood Infratentorial Ependymoma. PLoS One. 2016;11(7):e0158464.

71. Song L, Huang Q, Chen K, Liu L, Lin C, Dai T, Yu C, Wu Z, Li J. miR-218 inhibits the invasive ability of glioma cells by direct downregulation of IKK- $\beta$. Biochem Biophys Res Commun. 2010;402(1):135-40.

72. Venkataraman S, Birks DK, Balakrishnan I, Alimova I, Harris PS, Patel PR, Handler MH, Dubuc A, Taylor MD, Foreman NK. MicroRNA 218 acts as a tumor suppressor by targeting multiple cancer phenotype-associated genes in medulloblastoma. J Biol Chem. 2013;288(3):1918-28.

73. Uziel T, Karginov FV, Xie S, Parker JS, Wang Y-D, Gajjar A, He L, Ellison D, Gilbertson RJ, Hannon G. The miR-17 92 cluster collaborates with the Sonic Hedgehog pathway in medulloblastoma. Proc Natl Acad Sci. 2009; 106(8):2812-7

74. Kushner BH, Gilbert F, Helson L. Familial neuroblastoma. Case reports, literature review, and etiologic considerations. Cancer. 1986;57(9):1887-93.

75. Villamón E, Berbegall AP, Piqueras M, Tadeo I, Castel V, Djos A, Martinsson T, Navarro S, Noguera R. Genetic Instability and Intratumoral Heterogeneity in Neuroblastoma with MYCN Amplification Plus 11q Deletion. PLoS One. 2013;8(1):e53740

76. Fontana L, Fiori ME, Albini S, Cifaldi L, Giovinazzi S, Forloni M, Boldrini R, Donfrancesco A, Federici $V$, Giacomini P, et al. Antagomir-17-5p abolishes the growth of therapy-resistant neuroblastoma through p21 and BIM. PLoS One. 2008;3(5):e2236.

77. Stallings RL. MicroRNA Involvement in the Pathogenesis of Neuroblastoma: Potential for MicroRNA Mediated Therapeutics. Curr Pharm Des. 2009;15(4): 456-62

78. Chen Y, Stallings RL. Differential patterns of microRNA expression in neuroblastoma are correlated with prognosis, differentiation, and apoptosis. Cancer Res. 2007;67(3):976-83.

79. Welch C, Chen Y, Stallings RL. MicroRNA-34a functions as a potential tumor suppressor by inducing apoptosis in neuroblastoma cells. Oncogene. 2007; 26(34):5017-22.

80. Samuel N, Wilson G, Said Bl, Pan A, Deblois G, Fischer NW, Alexandrova R, Casallo G, Paton T, Lupien M, et al. Transcriptome-wide characterization of the endogenous miR-34A-p53 tumor suppressor network. 2016.

81. Wei JS, Song YK, Durinck S, Chen QR, Cheuk AT, Tsang P, Zhang Q, Thiele CJ, Slack A, Shohet J, et al. The MYCN oncogene is a direct target of miR34a. Oncogene. 2008;27(39):5204-13.
82. Bommer GT, Gerin I, Feng Y, Kaczorowski AJ, Kuick R, Love RE, Zhai Y, Giordano TJ, Qin ZS, Moore BB, et al. p53-mediated activation of miRNA34 candidate tumor-suppressor genes. Curr Biol. 2007;17(15):1298-307.

83. Sun F, Fu H, Liu Q, Tie Y, Zhu J, Xing R, Sun Z, Zheng X. Downregulation of CCND1 and CDK6 by miR-34a induces cell cycle arrest. FEBS Lett. 2008;582(10):1564-8.

84. Cole KA, Attiyeh EF, Mosse YP, Laquaglia MJ, Diskin SJ, Brodeur GM, Maris JM. A Functional Screen Identifies miR-34a as a Candidate Neuroblastoma Tumor Suppressor Gene. Mol Cancer Res. 2008;6(5):735-42.

85. Creevey L, Ryan J, Harvey H, Bray IM, Meehan M, Khan AR, Stallings RL. MicroRNA-497 increases apoptosis in MYCN amplified neuroblastoma cells by targeting the key cell cycle regulator WEE1. Mol Cancer. 2013;12:23.

86. Ayers D, Mestdagh P, Van Maerken T, Vandesompele J. Identification of miRNAs contributing to neuroblastoma chemoresistance. Computational and Structural Biotechnology Journal. 2015;13:307-19.

87. Yu HW, Cho WC. The emerging role of miRNAs in combined cancer therapy. Expert Opin Biol Ther. 2015;15(7):923-5.

88. Di Stefano C, Mirone G, Perna S, Marfe G. The roles of microRNAs in the pathogenesis and drug resistance of chronic myelogenous leukemia (Review). Oncol Rep. 2016;35(2):614-24.

89. Rubio R, Abarrategi A, Garcia-Castro J, Martinez-Cruzado L, Suarez C, Tornin J. Santos L, Astudillo A, Colmenero I, Mulero F, et al. Bone Environment is Essential for Osteosarcoma Development from Transformed Mesenchymal Stem Cells. STEM CELLS. 2014;32(5):1136-48.

90. Kaufmann WK, Kaufman DG. Cell cycle control, DNA repair and initiation of carcinogenesis. FASEB J. 1993;7(12):1188-91.

91. Lulla RR, Costa FF, Bischof JM, Chou PM, Bonaldo MdF, Vanin EF, Soares MB: Identification of Differentially Expressed MicroRNAs in Osteosarcoma. Sarcoma. 2011;2011:6. Article ID 732690. doi:10.1155/2011/732690.

92. Valeri N, Braconi C, Gasparini P, Murgia C, Lampis A, Paulus-Hock V, Hart Jonathan R, Ueno L, Grivennikov Sergei I, Lovat F, et al. MicroRNA-135b Promotes Cancer Progression by Acting as a Downstream Effector of Oncogenic Pathways in Colon Cancer. Cancer Cell. 2014;25(4):469-83.

93. Wu Q, Jin H, Yang Z, Luo G, Lu Y, Li K, Ren G, Su T, Pan Y, Feng B, et al. MiR150 promotes gastric cancer proliferation by negatively regulating the proapoptotic gene EGR2. Biochem Biophys Res Commun. 2010;392(3):340-5.

94. Bray I, Tivnan A, Bryan K, Foley NH, Watters KM, Tracey L, Davidoff AM, Stallings RL. MicroRNA-542-5p as a novel tumor suppressor in neuroblastoma. Cancer Lett. 2011:303(1):56-64

95. Volinia S, Galasso M, Sana ME, Wise TF, Palatini J, Huebner K, Croce CM. Breast cancer signatures for invasiveness and prognosis defined by deep sequencing of microRNA. Proc Natl Acad Sci. 2012;109(8):3024-9.

96. Duan Z, Choy E, Harmon D, Liu X, Susa M, Mankin H, Hornicek F. MicroRNA$199 a-3 p$ is downregulated in human osteosarcoma and regulates cell proliferation and migration. Mol Cancer Ther. 2011;10(8):1337-45.

97. Chang TC, Wentzel EA, Kent OA, Ramachandran K, Mullendore M, Lee KH, Feldmann G, Yamakuchi M, Ferlito M, Lowenstein CJ, et al. Transactivation of miR-34a by p53 broadly influences gene expression and promotes apoptosis. Mol Cell. 2007;26(5):745-52.

98. He L, He X, Lim LP, de Stanchina E, Xuan Z, Liang Y, Xue W, Zender L, Magnus J, Ridzon D, et al. A microRNA component of the p53 tumour suppressor network. Nature. 2007:447(7148):1130-4.

99. Raver-Shapira N, Marciano E, Meiri E, Spector Y, Rosenfeld N, Moskovits N, Bentwich Z, Oren M. Transcriptional activation of miR-34a contributes to p53-mediated apoptosis. Mol Cell. 2007;26(5):731-43.

100. Tarasov V, Jung $P$, Verdoodt B, Lodygin D, Epanchintsev A, Menssen A, Meister $\mathrm{G}$, Hermeking $\mathrm{H}$. Differential regulation of microRNAs by p53 revealed by massively parallel sequencing: miR-34a is a p53 target that induces apoptosis and G1-arrest. Cell Cycle. 2007;6(13):1586-93.

101. Corney DC, Flesken-Nikitin A, Godwin AK, Wang W, Nikitin AY. MicroRNA$34 \mathrm{~b}$ and MicroRNA-34c are targets of p53 and cooperate in control of cell proliferation and adhesion-independent growth. Cancer Res. 2007;67(18): 8433-8.

102. Kelly LC, Lazaro A, O'Sullivan MJ. What Do We Know about the Role of miRNAs in Pediatric Sarcoma? Int J Mol Sci. 2015;16(7):16593-621.

103. Jones KB, Salah Z, Sara DM, Galasso M, Gaudio E, Nuovo GJ, Lovat F, LeBlanc K, Palatini J, Randall RL, et al. MicroRNA signatures associate with pathogenesis and progression of osteosarcoma. Cancer Res. 2012;72(7):1865-77.

104. Rivera MN, Haber DA. Wilms' tumour: connecting tumorigenesis and organ development in the kidney. Nat Rev Cancer. 2005:5(9):699-712.

105. Buckley KS. Pediatric genitourinary tumors. Curr Opin Oncol. 2011;23(3):297-302. 
106. Hohenstein P, Pritchard-Jones K, Charlton J. The yin and yang of kidney development and Wilms' tumors. Genes Dev. 2015;29(5):467-82.

107. Wu MK, Sabbaghian N, Xu B, Addidou-Kalucki S, Bernard C, Zou D, Reeve AE, Eccles MR, Cole C, Choong CS, et al. Biallelic DICER1 mutations occur in Wilms tumours. J Pathol. 2013;230(2):154-64.

108. Senanayake U, Das S, Vesely P, Alzoughbi W, Fröhlich LF, Chowdhury P, Leuschner I, Hoefler G, Guertl B. miR-192, miR-194, miR-215, miR-200 C and miR-141 are downregulated and their common target ACVR2B is strongly expressed in renal childhood neoplasms. Carcinogenesis. 2012;33(5):1014-21

109. Kort EJ, Farber L, Tretiakova M, Petillo D, Furge KA, Yang XJ, Cornelius A, Teh BT. The E2F3-Oncomir 1 axis is activated in Wilms Tumor. Cancer Res. 2008;68(11):4034-8.

110. Murphy BL, Obad S, Bihannic L, Ayrault O, Zindy F, Kauppinen S, Roussel MF. Silencing of the miR-17 92 cluster family inhibits medulloblastoma progression. Cancer Res. 2013;73(23):7068-78.

111. Ludwig T, Eggenschwiler J, Fisher P, D'Ercole AJ, Davenport ML, Efstratiadis A. Mouse mutants lacking the type 2 IGF receptor (IGF2R) are rescued from perinatal lethality in lgf2 and lgf1r null backgrounds. Dev Biol. 1996;177(2):517-35.

112. Adams Brian D, Kasinski Andrea L, Slack Frank J. Aberrant Regulation and Function of MicroRNAs in Cancer. Curr Biol. 2014;24(16):R762-76.

113. Kobayashi A, Valerius MT, Mugford JW, Carroll TJ, Self M, Oliver G, McMahon AP. Six2 Defines and Regulates a Multipotent Self-Renewing Nephron Progenitor Population throughout Mammalian Kidney Development. Cell Stem Cell. 2008;3(2):169-81.

114. Urbach A, Yermalovich A, Zhang J, Spina CS, Zhu H, Perez-Atayde AR, Shukrun R, Charlton J, Sebire N, Mifsud W et al.: Lin28 sustains early renal progenitors and induces Wilms tumor. Genes \& Development 2014;28:971-82.

115. Hiyama E. Pediatric hepatoblastoma: diagnosis and treatment. Translational Pediatrics. 2014;3(4):293-9.

116. Garber JE, Li FP, Kingston JE, Krush AJ, Strong LC, Finegold MJ, Bertario L, Bulow S, Filippone Jr A, Gedde-Dahl Jr T, et al. Hepatoblastoma and familial adenomatous polyposis. J Natl Cancer Inst. 1988;80(20):1626-8.

117. Cohen Jr MM. Beckwith-Wiedemann syndrome: historical, clinicopathological, and etiopathogenetic perspectives. Pediatr Dev Pathol. 2005;8(3):287-304

118. Leichter AL, Purcell RV, Sullivan MJ, Eccles MR, Chatterjee A. Multi-platform microRNA profiling of hepatoblastoma patients using formalin fixed paraffin embedded archival samples. GigaScience. 2015;4:54.

119. Chatterjee A, Leichter AL, Fan V, Tsai P, Purcell RV, Sullivan MJ, Eccles MR. A cross comparison of technologies for the detection of microRNAs in clinical FFPE samples of hepatoblastoma patients. Scientific reports. 2015;5:10438.

120. von Frowein J, Pagel P, Kappler R, von Schweinitz D, Roscher A, Schmid I. MicroRNA-492 is processed from the keratin 19 gene and up-regulated in metastatic hepatoblastoma. Hepatology. 2011;53(3):833-42.

121. Gyugos M, Lendvai G, Kenessey I, Schlachter K, Halasz J, Nagy P, Garami M, Jakab Z, Schaff Z, Kiss A. MicroRNA expression might predict prognosis of epithelial hepatoblastoma. Virchows Arch. 2014;464(4):419-27.

122. Liu W, Chen S, Liu B. Diagnostic and prognostic values of serum exosomal microRNA-21 in children with hepatoblastoma: a Chinese population-based study. Pediatr Surg Int. 2016;32(11):1059-65.

123. Murray M, Bailey S, Raby K, Saini H, De Kock L, Burke G, Foulkes W, Enright A, Coleman N, Tischkowitz M. Serum levels of mature microRNAs in DICER1mutated pleuropulmonary blastoma. Oncogenesis. 2014;3(2):e87.

124. Shifeng H, Danni W, Pu C, Ping Y, Ju C, Liping Z. Circulating liver-specific miR-122 as a novel potential biomarker for diagnosis of cholestatic liver injury. PLoS One. 2013;8(9):e73133.

125. Cho WCS. MicroRNAs as therapeutic targets and their potential applications in cancer therapy. Expert Opin Ther Targets. 2012:16(8):747-59.

126. Shea A, Harish V, Afzal Z, Chijioke J, Kedir H, Dusmatova S, Roy A, Ramalinga $\mathrm{M}$, Harris B, Blancato J, et al. MicroRNAs in glioblastoma multiforme pathogenesis and therapeutics. Cancer Medicine. 2016;5(8):1917-46.

127. Darnell DK, Kaur S, Stanislaw S, Konieczka JK, Yatskievych TA, Antin PB. MicroRNA expression during chick embryo development. Dev Dyn. 2006; 235(11):3156-65

128. Kozomara A. Griffiths-Jones S: miRBase: integrating microRNA annotation and deep-sequencing data. Nucleic Acids Res. 2011;39(Database issue):D152-7.
129. Lewis BP, Burge CB, Bartel DP. Conserved Seed Pairing, Often Flanked by Adenosines, Indicates that Thousands of Human Genes are MicroRNA Targets. Cell. 2005;120(1):15-20.

130. Tsang JS, Ebert MS, van Oudenaarden A. Genome-wide dissection of microRNA functions and co-targeting networks using gene-set signatures. Mol Cell. 2010;38(1):140-53.

\section{Submit your next manuscript to BioMed Central and we will help you at every step:}

- We accept pre-submission inquiries

- Our selector tool helps you to find the most relevant journal

- We provide round the clock customer support

- Convenient online submission

- Thorough peer review

- Inclusion in PubMed and all major indexing services

- Maximum visibility for your research

Submit your manuscript at www.biomedcentral.com/submit
Biomed Central 